Anindita Mukherjee ${ }^{1}$, Rana Chatterjee ${ }^{2}$, Aramita $\mathrm{De}^{2}$, Satyajit Samanta ${ }^{2}$, Sachinta Mahato ${ }^{2}$, Nirnita Chakraborty Ghosal ${ }^{2}$, G. V. Zyryanov ${ }^{1,3}$, Adinath Majee ${ }^{2^{*}}$

${ }^{1}$ Institute of Chemical Engineering, Ural Federal University, 19 Mira St., Ekaterinburg, 620002, Russia ${ }^{2}$ Department of Chemistry, Visva-Bharati University, Santiniketan, 731235, India ${ }^{3}$ Postovsky Institute of Organic Synthesis UB RAS, 22 Kovalevskaya St., Ekaterinburg, 620219, Russia E-mail: adinath.majee@visva-bharati.ac.in

\title{
Conjugated Addition of Amines to Electron Deficient Alkenes: A Green Approach
}

A very simple approach has been developed for conjugate addition of a variety of aliphatic and aromatic amines to electron deficient alkenes in presence tea extract at room temperature. General applicability, operational simplicity, aqueous media, mild reaction conditions, environment friendly, high yields and applications of inexpensive and easily available catalyst are the advantages of the present procedure.

Keywords: Michael addition; amines; a, $\beta$-ethylenic compounds; tea extract

Received: 17.06.2017; accepted: 26.06.2017; published: 14.07.2017.

(C) Anindita Mukherjee, Rana Chatterjee, Aramita De, Satyajit Samanta, Sachinta Mahato, Nirnita Chakraborty Ghosal, Zyryanov G. V., Adinath Majee, 2017

\section{Introduction}

The formation of carbon-nitrogen bond is very important task in organic synthesis and conjugate addition of amines to electron deficient alkenes is an efficient route to develop the carbonnitrogen bond [1]. As a consequence, $\beta$-amino ketone, nitriles, amide and carboxylic ester functionalities occur in many natural products [2-4]. It provides an easy route to produce $\beta$-amino derivatives, which are attractive for their use as synthetic intermediates of anticancer agents, antibiotics and other drugs [5, 6]. It is noteworthy to mention that the classical method for the preparation of $\beta$-amino derivatives is via Mannich reaction [7]. The conjugate addition of amine to electron deficient alkenes is an alternate route to synthesize $\beta$-amino derivatives. In comparison with Michael reaction the conjugate addition of amine to electron deficient alkenes is, in contrast, atom economical and easy to operate. But usually both these additions are carried out in presence of a strong base or acid $[8,9]$. Several methods are available in the literature by using different catalysts such as $\mathrm{Yb}(\mathrm{OTf})_{3}[10], \mathrm{CeCl}_{3} \cdot 7 \mathrm{H}_{2} \mathrm{O}-\mathrm{NaI}$ [11], $\mathrm{InCl}_{3}[12], \mathrm{Cu}(\mathrm{OTf})_{2}[13,14]$, CAN [15], KF/alumina [16,17], $\mathrm{LiClO}_{4}$ [18], $\mathrm{Bi}(\mathrm{OTf})_{3}[19], \mathrm{Bi}(\mathrm{NO})_{3}[20], \mathrm{SmI}_{2}[21]$, $\mathrm{Cu}(\mathrm{acac})_{2} /$ ionic liquid [22], ionic liquid/ quaternary ammonium salt $[23,24]$, boric acid [25], borax [26], $\mathrm{ZrOCl}_{2} \cdot 8 \mathrm{H}_{2} \mathrm{O}$ [27], 
$\beta$-cyclodextrin [28], bromodimethylsulfonium bromide [29], [ $\mathrm{HP}\left(\mathrm{HNCH}_{2} \mathrm{CH}_{2}\right)_{3} \mathrm{~N}$ ] $\mathrm{NO}_{3}$ [30], $\mathrm{MnCl}_{2}$ [31] etc. Although these methods have their own advantages and quite useful, but some of these methods used a large excess of reagents, hazardous solvents such as acetonitrile or 1,2-dichloroethane, require long time and harsh reaction. Ranu et al. reported these addition in the absence of catalysts or water as the reaction medium, but due to the solubility problem of organic compounds the scope of the method is limited $[32,33]$. So far, the reported methodologies are effective for either aromatic amines or aliphatic amines. So, in a consequence, development of a general, simple and environmentally benign method is highly desirable. Considering the environmentally consciousness in chemical research, reactions in water have attracted much attention in recent times $[34,35]$. In 2008, Varma et al. reported that tea and coffee extract can be used as good stabilizer for green synthesis of silver and palladium na- noparticles [36]. The authors first synthesized nanoparticles in presence of tea and coffee extract. This observation promoted us to consider the tea extract for some organic reactions. Interestingly, from the recent research we observed according to normal expectation that the extraction of normal tea is acidic in nature [37]. This observation motivated us to investigate the catalytic role of tea extract for simple organic reaction. So, in continuation of our research to develop green methodology [38-41], we have observed that tea extract is very useful as solvent as well as catalyst for conjugate addition of a variety of amines to different Michael acceptors (Fig. 1).

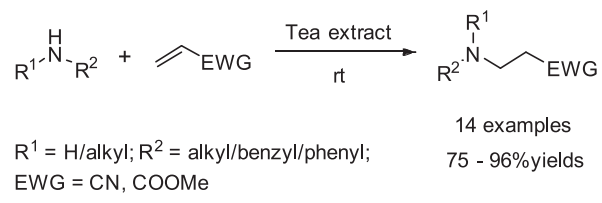

Fig. 1. Tea extract mediated conjugated addition of amines to electron deficient alkenes

\section{Results and discussion}

First of all, we prepared the required tea extract. In a typical experimental procedure, $2 \mathrm{~g}$ of tea leaves were dissolved in $20 \mathrm{~mL}$ of water and boiled it for 10-15 min. After filtration we got the extract which was used for the said reactions. It was observed that $2 \mathrm{~mL}$ of tea extract is sufficient to get the best result. Several structurally varied amines were coupled with the wide range of $\alpha$, $\beta$-ethylenic compounds and the results are summarized in Table 1. A variety of aliphatic amines was examined to prove the general applicability of this present procedure and the corresponding Michael adducts were isolated in excellent yields within a short reaction time. The aliphatic primary amines such as benzylamine, butylamine and cyclohexylamine were treated with different Michael acceptors and corresponding monoadducts were isolated in good yields (Table 1, entries 1-5). The reaction of open chain bulky secondary amine like diisopropylamine proceeded very well (entries 6, 7). Cyclic secondary amines such as piperidine and morpholine underwent facile additions with acrylonitrile and acrylic esters respectively (Table 1 , entries 6,7). Aromatic amines are less reactive than aliphatic amines and took long reaction time. Both activated and weakly activated anilines were investigated. The reactions proceeded smoothly at room temperature and the products were 
obtained in excellent yields. Several sub- yields under present reaction condistituted anilines such as methyl and me- tions (Table 1, entries 10-14). Acid senthoxy anilines underwent efficient ad- sitive functional group in aniline such as ditions with acrylonitrile and methyl 3,4-(methylenedioxy)aniline also reacted acrylate giving only monoadduct in high well to give the desired product in good

Table 1

Tea extract-mediated Michael addition of amines to conjugated alkenes ${ }^{\mathrm{a}}$

\begin{tabular}{|c|c|c|c|c|c|}
\hline Entry & Amine & Alkene & Product & $\begin{array}{l}\text { Time } \\
{[\mathrm{min}(\mathrm{h})]}\end{array}$ & Yield $(\%)^{b}$ \\
\hline 1 & $\mathrm{PhCH}_{2} \mathrm{NH}_{2}$ & $\mathrm{CN}$ & $\mathrm{PhC}$ & 20 & 92 \\
\hline 2 & $\mathrm{PhCH}_{2} \mathrm{NH}_{2}$ & COOMe & $\mathrm{PhC}$ & 40 & 90 \\
\hline 3 & & $\mathrm{CN}$ & & 20 & 96 \\
\hline 4 & & $\mathrm{CN}$ & & 20 & 96 \\
\hline 5 & & CoOMe & & 50 & 90 \\
\hline 6 & & $C N$ & & 15 & 95 \\
\hline 7 & & COOMe & & 20 & 94 \\
\hline 8 & & $\mathrm{CN}$ & & 10 & 96 \\
\hline 9 & & CoOMe & & 20 & 90 \\
\hline 10 & $\mathrm{PhNH}_{2}$ & $\mathrm{CN}$ & & (18) & 75 \\
\hline 11 & $\mathrm{PhNH}_{2}$ & $\mathrm{CO}_{2} \mathrm{Me}$ & & (20) & 85 \\
\hline 12 & 4-(OMe)- $\mathrm{C}_{6} \mathrm{H}_{4} \mathrm{NH}_{2}$ & $\mathrm{CN}$ & & (24) & 75 \\
\hline 13 & 4-Me- $\mathrm{C}_{6} \mathrm{H}_{4} \mathrm{NH}_{2}$ & $\mathrm{CN}$ & & (24) & 80 \\
\hline 14 & & coOMe & & (12) & 88 \\
\hline
\end{tabular}

aReaction conditions: $2 \mathrm{mmol}$ of amine and $2 \mathrm{mmol}$ of alkene were stirred in $2 \mathrm{~mL}$ of tea extract at room temperature; ${ }^{\mathrm{b}}$ Isolated yields. 
yields keeping methylenedioxy group unaffected (Table 1, entry 14). With regard to Michael acceptors, a wide range of structurally diverse electron deficient alkenes was used such as $\alpha, \beta$-unsaturated nitrile and carboxylic ester. In general, the reactions are very clean. Both aliphatic and aromatic amines give the products in equally fair yields. In particular, in the case of primary amines the method pro- duces the corresponding $\beta$-amino derivatives without the problem of double-conjugate addition. We have not observed any by-products for all reaction combinations which are supported by high yields of the protocol. All of the known synthesized compounds have been characterized by spectral data and the new compounds by spectral and analytical data.

\section{Conclusions}

In conclusion, we have developed a tea extract-mediated a highly efficient methodology for the synthesis of $\beta$-amino derivatives under milder reaction conditions at room temperature. General applicability, operational simplicity, aqueous media, mild reaction conditions, environment friendly, high yields, and applica- tions of inexpensive and easily available catalyst are the advantages of the present procedure. We believe this aza-Michael reactions are of significant importance in both synthetic chemistry and industrial processes for the synthesis of $\beta$-amino derivatives.

\section{Experimental}

General: ${ }^{1} \mathrm{H}$ NMR $(300 \mathrm{MHz})$ and ${ }^{13} \mathrm{C}$ NMR $(75 \mathrm{MHz})$ spectra were run in $\mathrm{CDCl}_{3}$ solutions. IR spectra were taken as $\mathrm{KBr}$ plates. Elemental analyses were done by Perkin-Elmer autoanalyzer. Column chromatography was performed on silica gel (60-120 mesh, SRL, India). $\mathrm{MnCl}_{2} \cdot 4 \mathrm{H}_{2} \mathrm{O}$ was purchased from NICE Chemicals, India. Tea leaves were purchased from market. Amines and alkenes are all commercial materials. All liquid reagents were distilled before use.

Preparation of tea extract: $2 \mathrm{~g}$ of tea leaves (any marketed) were dissolved in 20 $\mathrm{mL}$ of water and boiled it for 10-15 min. After filtration we got the extract which was used for the reactions.

General procedure for the synthesis of $\beta$-amino derivatives: $A$ mixture of amine $(2 \mathrm{mmol})$ and alkene $(2 \mathrm{mmol})$ was stirred in $2 \mathrm{~mL}$ of tea extract at room temperature as required for completion
(TLC). After completion of the reaction the reaction mixture was extracted with ethyl acetate $(40 \mathrm{~mL})$. The extract was washed with water $(2 \times 10 \mathrm{~mL})$ and brine solution $(1 \times 10 \mathrm{~mL})$ and dried over anhydrous sodium sulphate. Evaporation of solvent followed by short column chromatography of the crude product over silica gel (hexane/ ethyl acetate) furnished the analytically pure product. The known compounds have been identified by comparison of spectra data (IR and NMR). The spectral and analytical data of the compounds which are not readily found provided below.

\section{3-(Cyclohexylamino)propanenitrile} (Table 1, entry 4): Colorless oil; IR2928, $2246,1722,1666,1558,1455 \mathrm{~cm}^{-1} ;{ }^{1} \mathrm{H}$ NMR $\delta 2.85(\mathrm{t}, J=5.1 \mathrm{~Hz}, 2 \mathrm{H}), 2.45(\mathrm{t}, J=$ $5.1 \mathrm{~Hz}, 2 \mathrm{H}), 2.43(\mathrm{~m}, 1 \mathrm{H}) 1.80-1.63(\mathrm{~m}$, $5 \mathrm{H}), 1.25-1.16(\mathrm{~m}, 6 \mathrm{H})$. Calculated for 
$\mathrm{C}_{9} \mathrm{H}_{16} \mathrm{~N}_{2}: \mathrm{C}, 71.01 ; \mathrm{H}, 10.59 ; \mathrm{N}, 18.40 \%$. Found: C, 60.82; H, 10.35; N, 18.13\%.

3-(4-Methoxy-phenylamino)-propanenitrile (Table 1, entry 12): Colorless liquid; IR3377, 2244, 1842, 1617, 1514, $1289 \mathrm{~cm}^{-1} ;{ }^{1} \mathrm{H}$ NMR $\delta 6.80(\mathrm{~d}, J=$ $5.1 \mathrm{~Hz}, 2 \mathrm{H}) .6 .61(\mathrm{~d}, \mathrm{~J}=5.1 \mathrm{~Hz}, 2 \mathrm{H}), 3.75$ $(\mathrm{s}, 3 \mathrm{H}), 3.47(\mathrm{t}, J=4.8 \mathrm{~Hz}, 2 \mathrm{H}), 2.61(\mathrm{t}$, $J=4.8 \mathrm{~Hz}, 2 \mathrm{H}),(\mathrm{N}-\mathrm{H})$ not identified; ${ }^{13} \mathrm{C}$ NMR $\delta 152.9,140.3,118.5,115.1$ (2C), 114.8 (2C), 55.8, 40.8, 18.2. Calculated for $\mathrm{C}_{10} \mathrm{H}_{12} \mathrm{~N}_{2} \mathrm{O}: \mathrm{C}, 68.16 ; \mathrm{H}, 6.86 ; \mathrm{N}, 15.90 \%$. Found: C, 67.98; H, 6.53; N, $15.62 \%$.
3-(4-Methyl-phenyla mino)-propanenitrile (Table 1, entry 13): Colorless liquid; IR3559, 2253, 1615, 1522, 1404 $\mathrm{cm}^{-1}$; ${ }^{1} \mathrm{H}$ NMR $\delta 7.00(\mathrm{~d}, J=6.0 \mathrm{~Hz}, 2 \mathrm{H})$, $6.53(\mathrm{~d}, J=6.0 \mathrm{~Hz}, 2 \mathrm{H}), 3.47(\mathrm{~d}, \mathrm{~J}=5.1 \mathrm{~Hz}$, $2 \mathrm{H}), 2.60(\mathrm{~d}, J=5.1 \mathrm{~Hz}, 2 \mathrm{H}), 2.24(\mathrm{~s}, 3 \mathrm{H})$ $(\mathrm{N}-\mathrm{H})$ not identified; ${ }^{13} \mathrm{C}$ NMR $\delta 143.9$, 130.2 (2C), 127.7, 118.5, 113.2 (2C), 40.0, 20.4, 18.0. Calculated for $\mathrm{C}_{10} \mathrm{H}_{12} \mathrm{~N}_{2}$ : C, 74.97; H, 7.55; N, 17.48\%. Found: C, 74.63; H, 7.38; N, $17.16 \%$.

\section{Acknowledgements}

A. Majee acknowledges financial support from the DST-RSF Major Research Project (Ref. No. INT/RUS/RSF/P-08). G. V. Zyryanov acknowledges the Rus- sian Science Foundation - Russia (Ref. № 16-43-02020) for funding. We are thankful to the DST-FIST and UGC-SAP programmes.

\section{References}

1. Permutter P. Conjugated Addition Reactions in Organic Synthesis. Oxford: Pergamon Press; 1992. 373 p.

2. Bartoli G, Cimarelli C, Marcantoni E, Palmieri G, Petrini M. Chemo- and diastereoselective reduction of $\beta$-enamino esters: A convenient synthesis of both cis- and trans- $\gamma$-amino alcohols and $\beta$-amino esters. J Org Chem. 1994;59(18):5328-35. DOI:10.1021/jo00097a039.

3. Elango S, Yan TH. A short synthesis of $(+)$-narciclasine via a strategy derived from stereocontrolled epoxide formation and $\mathrm{SnCl}_{4}$-catalyzed arene-epoxide coupling. J Org Chem. 2002;67(20):6954-9. DOI:10.1021/jo020155k.

4. Elango S, Yan TH. A short synthesis of (+)-lycoricidine. Tetrahedron. 2002;58(36):7335-8. DOI:10.1016/S0040-4020(02)00736-6.

5. Banik BK, Becker FF, Banik I. Synthesis of anticancer $\beta$-lactams: Mechanism of action. Bioorg Med Chem. 2004;12(10):2523-8. DOI:10.1016/j.bmc.2004.03.033.

6. Graul A, Castaner J. Atorvastatin calcium. Hypolipidemic HMG-CoA reductase inhibitor. Drugs Future. 1997;22(9):956. PMID:9399600.

7. Ishitani H, Ueno M, Kobayashi S. Enantioselective mannich-type reactions using a novel chiral zirconium catalyst for the synthesis of optically active $\beta$-amino acid derivatives. J Am Chem Soc. 2000;122(34):8180-6. DOI:10.1021/ja001642p.

8. Jenner G. Catalytic high pressure synthesis of hindered $\beta$-aminoesters. Tetrahedron Lett. 1995;36(2):233-6. DOI:10.1016/0040-4039(94)02215-W.

9. D’Angelo J, Maddaluno J. Enantioselective Synthesis of B-Amino Esters through High-Pressure-Induced Addition of Amines to A, B-Ethylenic Esters. J Am Chem Soc. 1986;108(25):8112-4. DOI:10.1021/ja00285a051. 
10. Matsubara S, Yoshiyoka M, Utimoto K. Lanthanoid Triflate Catalyzed Conjugate Addition of Amines to $\alpha, \beta$-Unsaturated Esters. A Facile Route to Optically Active $\beta$-Lactam. Chem Lett. 1994;23(5):827-30. DOI:10.1246/cl.1994.827.

11. Bartoli G, Bartolacci M, Giuliani A, Marcantoni E, Massimo M, Torregiani E. Improved heteroatom nucleophilic addition to electron-poor alkenes promoted by $\mathrm{CeCl}_{3} \cdot 7 \mathrm{H}_{2} \mathrm{O} / \mathrm{NaI}$ system supported on alumina in solvent-free conditions. J Org Chem. 2005;70(1):169-74. DOI:10.1021/jo048329g.

12. Loh TP, Wei LL. Indium trichloride-catalyzed conjugate addition of amines to a, $\beta$-ethylenic compounds in water. Synlett. 1998;9:975-6. DOI:10.1016/j.tetlet.2005.03.112.

13. Wabnitz TC, Spencer JB. Convenient synthesis of Cbz-protected $\beta$-amino ketones by a copper-catalysed conjugate addition reaction. Tetrahedron Lett. 2002;43(21):38914. DOI:10.1016/S0040-4039(02)00654-8.

14. Xu LW, Li JW, Xia CG, Zhou SL, Hu XX. Efficient Copper-Catalyzed Chemo Selective Conjugate Addition of Aliphatic Amines to $\alpha, \beta$-Unsaturated Compounds in Water. Synlett. 2003;25:2425-7. DOI:10.1055/s-2003-42125.

15. Duan Z, Xuan X, Li T, Yang C, Wu Y. Cerium(IV) ammonium nitrate (CAN) catalyzed aza-Michael addition of amines to $\alpha, \beta$-unsaturated electrophiles. Tetrahedron Lett. 2006;47(31):5433-6. DOI:10.1016/j.tetlet.2006.05.182.

16. Yang L, Xu LW, Xia CG. Highly efficient $\mathrm{KF} / \mathrm{Al}_{2} \mathrm{O}_{3}$-catalyzed versatile hetero-Michael addition of nitrogen, oxygen, and sulfur nucleophiles to $\alpha, \beta$-ethylenic compounds. Tetrahedron Lett. 2005;46(19):3279-82. DOI:10.1016/j.tetlet.2005.03.112.

17. Shaikh NS, Deshpande VH, Bedekar AV. Clay catalyzed chemoselective Michael type addition of aliphatic amines to a, $\beta$-ethylenic compounds. Tetrahedron. 2001;57(43):9045-8. DOI:10.1016/S0040-4020(01)00911-5.

18. Azizi N, Saidi MR. $\mathrm{LiClO}_{4}$ accelerated Michael addition of amines to $a$, $\beta$-unsaturated olefins under solvent-free conditions. Tetrahedron. 2004;60(2):383-7. DOI:10.1016/j.tet.2003.11.012.

19. Varala R, Alam MM, Adapa SR. Chemoselective Michael type addition of aliphatic amines to $\alpha, \beta$-ethylenic compounds using bismuth triflate catalyst. Synlett. 2003;5:720-2. DOI:10.1055/s-2003-38345.

20. Srivastava N, Banik BK. Bismuth nitrate-catalyzed versatile Michael reactions. J Org Chem. 2003;68(6):2109-14. DOI:10.1021/jo026550s.

21. Reboule I, Gil R, Collin J. Aza-Michael reactions catalyzed by samarium diiodide. Tetrahedron Lett. 2005;46(45):7761-4. DOI:10.1016/j.tetlet.2005.09.039.

22. Kantam ML, Neeraja V, Kavita B, Neelima B, Chaudhuri MK, Hussain S. Cu(acac)2 immobilized in ionic liquids: A recoverable and reusable catalytic system for aza-Michael reactions. Adv Synth Catal. 2005;347(6):763-6. DOI:10.1002/adsc.200404361.

23. Xu LW, Li JW, Zhou SL, Xia CG. A green, ionic liquid and quaternary ammonium salt-catalyzed aza-Michael reaction of $\alpha, \beta$-ethylenic compounds with amines in water. New J Chem. 2004;28(2):183-4. DOI:10.1039/b312047c.

24. Karodia N, Liu X, Ludley P, Pletsas D, Stevenson G. The ionic liquid ethyltri- $n$-butylphosphonium tosylate as solvent for the acid-catalysed hetero-Michael reaction. Tetrahedron. 2006;62(48):11039-43. DOI:10.1016/j.tet.2006.09.052. 
25. Chaudhuri MK, Hussain S, Kantam ML, Neelima B. Boric acid: A novel and safe catalyst for aza-Michael reactions in water. Tetrahedron Lett. 2005;46(48):8329-31. DOI:10.1016/j.tetlet.2005.09.167.

26. Hussain S, Bharadwaj SK, Chaudhuri MK, Kalita H. Borax as an efficient metalfree catalyst for hetero-Michael reactions in an aqueous medium. Eur J Org Chem. 2007;2:374-8. DOI:10.1002/ejoc.200600691.

27. Hashemi MM, Eftekhari-Sis B, Abdollahifar A, Khalili B. $\mathrm{ZrOCl}_{2} \cdot 8 \mathrm{H} 2 \mathrm{O}$ on montmorillonite K10 accelerated conjugate addition of amines to $\alpha, \beta$-unsaturated alkenes under solvent-free conditions. Tetrahedron. 2006;62(4):672-7. DOI:10.1016/j. tet.2005.10.006.

28. Surendra K, Krishnaveni NS, Sridhar R, Rao KR. $\beta$-Cyclodextrin promoted azaMichael addition of amines to conjugated alkenes in water. Tetrahedron Lett. 2006;47(13):2125-7. DOI:10.1016/j.tetlet.2006.01.124.

29. Khan AT, Parvin T, Gazi S, Choudhury LH. Bromodimethylsulfonium bromide mediated Michael addition of amines to electron deficient alkenes. Tetrahedron Lett. 2007;48(22):3805-8. DOI:10.1016/j.tetlet.2007.03.163.

30. Fetterly BM, Jana NK, Verkade JG. [HP( $\left.\left.\mathrm{HNCH}_{2} \mathrm{CH}_{2}\right)_{3} \mathrm{~N}\right] \mathrm{NO}_{3}$ : An efficient homogeneous and solid-supported promoter for aza and thia-Michael reactions and for Strecker reactions. Tetrahedron. 2006;62(2-3):440-56. DOI:10.1016/j. tet.2005.09.117.

31. Roy A, Kundu D, Kundu SK, Majee A, Hajra A. Manganese (II) chloride-catalyzed conjugated addition of amines to electron deficient alkenes in methanolwater medium. The Open Catalysis Journal.2010;3(1):34-9. DOI:10.2174/187621 4X01003010034.

32. Ranu BC, Dey SS, Hajra A. Solvent-free, catalyst-free Michael-type addition of amines toelectron-deficient alkenes. ARKIVOC. 2002;7:76-81. DOI:10.3998/ ark.5550190.0003.709.

33. Ranu BC, Banerjee S. Significant rate acceleration of the aza-Michael reaction in water. Tetrahedron Lett. 2007;48(1):141-3. DOI:10.1016/j.tetlet.2006.10.142.

34. Kobayashi S, Manabe K. Development of novel Lewis acid catalysts for selective organic reactions in aqueous media. Acc Chem Res. 2002;35(2):209-17. DOI:10.1021/ ar000145a.

35. Kobayashi S, Sugiura M, Kitagawa H, Lam WWL. Rare-earth metal triflates in organic synthesis. Chem Rev. 2002;102(6):2227-302. DOI:10.1021/cr010289i.

36. Mallikarjuna NN, Varma RS. Green synthesis of silver and palladium nanoparticles at room temperature using coffee and tea extract. Green Chem. 2008;10(8):859-62. DOI:10.1039/b804703k.

37. Vuong QV, Golding JB, Stathopoulos CE, Roach PD. Effects of aqueous brewing solution $\mathrm{pH}$ on the extraction of the major green tea constituents. Food Res Int. 2013;53(2):713-9. Doi:10.1016/j.foodres.2012.09.017.

38. Ghosal NC, Santra S, Das S, Hajra A, Zyryanov GV, Majee A. Organocatalysis by an aprotic imidazolium zwitterion: Regioselective ring-opening of aziridines and applicable to gram scale synthesis. Green Chem. 2016;18(2):565-74. DOI:10.1039/ c5gc01323b. 
39. Santra S, Kopchuk DS, Kovalev IS, Zyryanov GV, Majee A, Charushin VN, Chupakhin ON. Solvent-free synthesis of pillar[6]arenes. Green Chem. 2016;18(2):423-6. DOI:10.1039/c5gc01505g.

40. Mahato S, Santra S, Chatterjee R, Zyryanov GV, Hajra A, Majee A. Brønsted acidic ionic liquid-catalyzed tandem reaction: an efficient approach towards regioselective synthesis of pyrano[3,2-c]coumarins under solvent-free conditions bearing lower E-factors. Green Chem. Forthcoming 2017. DOI:10.1039/c7gc01158j.

41. Santra S, Rahman M, Roy A, Majee A, Hajra A. Nano-indium oxide: An efficient catalyst for one-pot synthesis of 2,3-dihydroquinazolin-4(1H)-ones with a greener prospect. Catal Commun. 2014;49:52-7. DOI:10.1016/j.catcom.2014.01.032.

\section{Cite this article as (как цитировать эту статью)}

Mukherjeel A, Chatterjeel R, De A, Samantal S, Mahatol S, Ghosal NC, Zyryanov GV, Majee A. Conjugated Addition of Amines to Electron Deficient Alkenes: A Green Approach. Chimica Techno Acta. 2017:4(2);140-147. DOI: 10.15826/ chimtech.2017.4.2.029. 